\title{
Perkütan Ecmo Uygulanması Sırasında Profilaktik Ekstremite Koruyucu Kanülasyon
}

\section{Prodhylactic Limb Salvage Canulattion During Percutaneus ECMO Application}

\author{
İlker İNCE ${ }^{1}$, Ali BULUT ${ }^{1}$, İlker AKAR ${ }^{2}$, Cengizhan BAYYURT ${ }^{1}$, Senan HÜSEYNOV ${ }^{1}$, \\ Ugursay KIZILTEPE ${ }^{1}$
}

${ }^{1}$ Ankara Dışkapı Yıldırım Beyazıt Eğitim Araştırma Hastanesi Kalp Damar Cerrahi Kliniği, ANKARA

${ }^{2}$ Gaziosmanpaşa Üniversitesi Kalp Damar Cerrahi Anabilim Dalı, TOKAT

\section{Corresponding Author:}

Dr. İlker INCE

$\begin{array}{llr}\text { Ankara } & \text { Dışkapı } & \text { Yıldırım } \\ \text { Beyazıt } & \text { Eğitim } & \text { Araştırma } \\ \text { Hastanesi Kalp Damar Cerrahi } \\ \text { Kliniği, ANKARA }\end{array}$

Tel: $\quad+90 \quad 356 \quad 2129500$

Dahili:7325

Fax: 03562122142

e-mail:

ilkerince78@hotmail.com

Başvuru Tarihi/Received : 23-02-2015

Düzeltme Tarihi/Revised: 17-03-2015

Kabul Tarihi/Accepted: 18-03-2015

\section{Sayın Editör,}

Beden dışı yaşam destek sistemleri arasında ülkemizde ve dünyada en sık olarak kullanılan yöntem ekstrakorporeal membran oksijenasyonudur (ECMO). Temel endikasyon olarak yeterli sıv1 replasmanı, inotropik ajan kullanımı ve intraaortik balon pompası desteğine rağmen hemodinamik stabilizasyonu sağlanamayan kardiyak indeksi $21 \mathrm{t} / \mathrm{dk} / \mathrm{m}^{2}$ 'nin altında olan tüm hastalarda ECMO kullanılabilir. İlk uygulamadan günümüze kadar yaklaşık 23000 yenidoğanda kullanılmış olmasına rağmen, günümüzde artık gelişmiş ventilatör stratejileri, inhale nitrik oksitin yaygınlaşması gibi nedenlerle pulmoner destekten ziyade, kalp cerrahisi sonrası kardiyojenik şoktaki hastalarda kardiyak destek amaçlı olarak kullanılmaktadır (1).

Ekstrakorporeal membran oksijenasyonu pompa, oksijenatör, 1s1 değiştirici, arteryel ve venöz kanül, tubing set, basınç sistemi ve hava kabarcığ 1 dedektöründen oluşan kapalı devre bir sistemdir. Kardiyopulmoner baypas'tan farklı olarak rezervuar gerektirmediğinden prime volüm miktarı daha azdır, aktive pıhtılaşma zamanı: 180-220 saniye arasında kalması yeterli olduğundan kanama komplikasyonları daha az beklenir, normotermide optimal hematokrit seviyesi sağlandığında tam satüre hemoglobin sağlandığında oksijen desteği maksimize edilir.

Veno-arteryel ECMO, günümüzde artık tüm ECMO uygulamalarının \%98'ini oluşturmaktadır. Kanülasyon kardiyopulmoner baypastan ayrılamayan hastalarda santral olarak da yapılabilirken, perkütan olarak periferik yoldan uygulama ve hibrid uygulama da söz konusudur. Resüsitasyon amaçlı olarak ECMO takımları tarafından periferik yoldan uygulanmaktadır (2).

Erişkin hastalarda, femoral arter ve ven yolu ile perkütan periferik ECMO uygulanan hasta grubunda, kanülasyon yapilan ekstremitede gelişebilen iskemi, ilerleyen dönemde komplikasyonlara yol açabilmektedir. $\mathrm{Bu}$ komplikasyonların önüne geçilebilmek için iskemi gelişen ekstremitenin distaline arteryel kanülden bir ara hat çekilerek distal perfüzyonun yapılması önerilen bir yöntemdir.

Kliniğimizde ECMO uygulanan hastalarda distal vasküler yatağın perfüzyonu, rutin olarak kanülasyon öncesi yapılmaktadır.

Bu işlemin avantajları;

1- Kanülasyon sonrası oluşabilecek arteryel kollaps nedeni ile mükerrer ponksiyonları engeller.

2- Sheat girişimine bağlı arteryel rüptür ve disseksiyon riskini minimize eder.

3- İskemi ve iskemi reperfüzyon hasarına bağlı oluşabilecek asidoz ve miyokardiyal depresyon riskini minimize eder.

4- Zaten sinırda rezervi olan hastalarda komplikasyonlar nedeni ile yapılabilecek cerrahi müdahale sayısını azaltır.

$\mathrm{Bu}$ sebeplerden ötürü perkütan ECMO uygulamasında kanülasyon öncesi dönemde, ultrasonografi eşliğinde (Resim 2) yüzeyel femoral arter 
Çağdaş Tıp Dergisi 2015;5(Ek): CR 107-108

İnce ve ark.

DOI: $10.16899 /$ ctd. 60767

kateterizasyonu ile perfüzyonun sağlanmasının ekstremite ile ilgili komplikasyonların önüne geçilmesinde yararlı bir yöntem olduğu kanaatindeyiz.

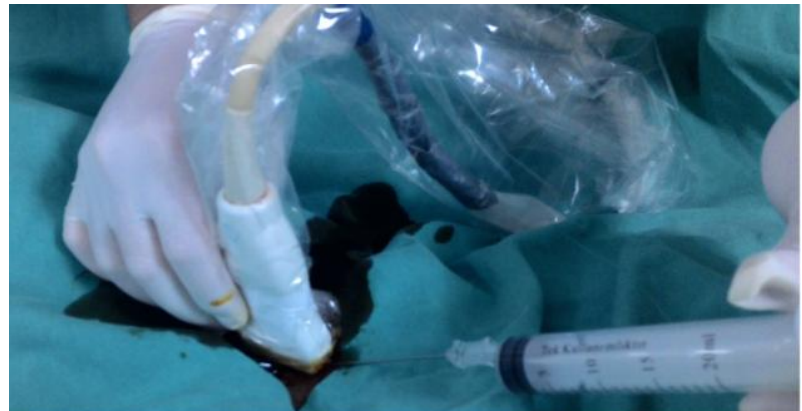

Resim 1: Ultrasonografi eşliğinde yatak baş1 kanülasyon öncesi yüzeyel femoral arter ponksiyonu

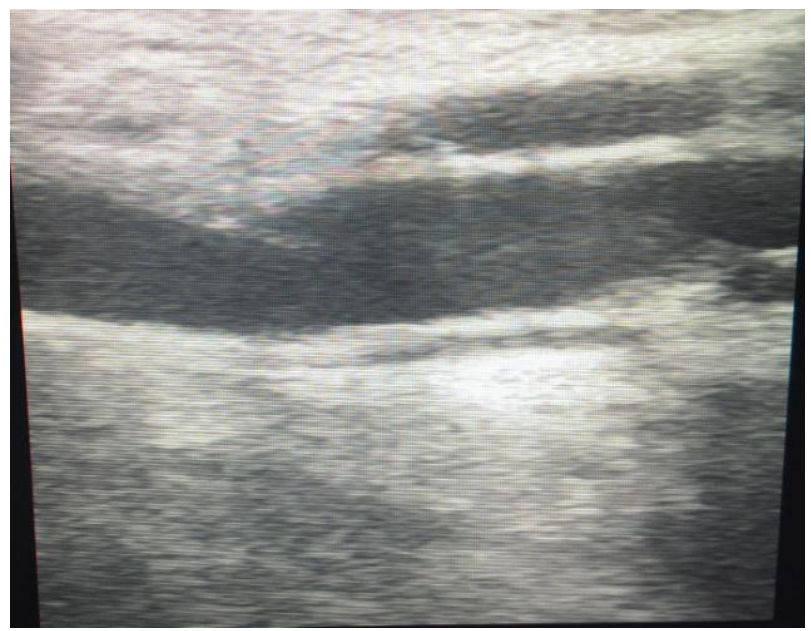

Resim 2: Femoral arteryel kanülasyon ponksiyon ve kanülasyonda USG'nin kullanımı

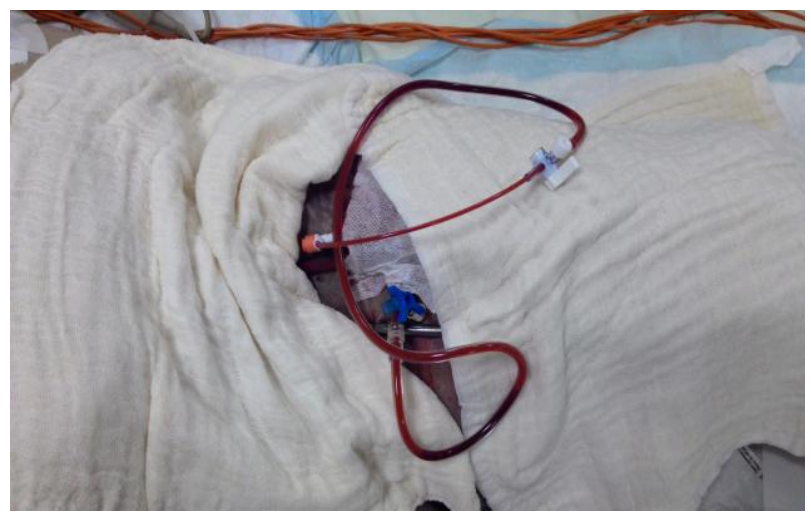

Resim 3: Perkütan kanülasyon ve distal ekstremite perfüzyonu

\section{Kaynaklar:}

1- Çeviri: İnce D.A. (Wolf G.K, Arnold J. H.) Ekstrakorporeal membran oksijenasyonu (Bölüm 39). Neonatoloji el kitabı, Ankara: Güneş Tıp Kitabevi, 2014.

2- Sezgin A. ECMO: Ekstrakorporal Membran Oksijenasyonu (Kısım V, Bölüm 5). Demirkılıç U. Ekstrakorporeal Dolaşım, Ankara: Eflatun Yayınevi, 2008 . 